\title{
Gene Targeting in Mice Reveals a Requirement for Angiotensin in the Development and Maintenance of Kidney Morphology and Growth Factor Regulation
}

Fumio Niimura, ${ }^{\star}$ Patricia A. Labosky, ${ }^{\star \star \star ~ J u n j i ~ K a k u c h i, ~}{ }^{*}$ Soichiro Okubo, ${ }^{\circ}$ Hiroaki Yoshida, * Tsuyoshi Oikawa, 5 Toshihiro Ichiki," Allen J. Naftilan, ' Agnes Fogo, ${ }^{5}$ Tadashi Inagami," Brigid L. M. Hogan, ${ }^{\ddagger \star \star}$ and lekuni Ichikawa* Departments of *Pediatrics, ${ }^{\ddagger}$ Cell Biology, ${ }^{8}$ Pathology, "Biochemistry, 'Medicine, and ${ }^{*}{ }^{*}$ Howard Hughes Medical Institute, Vanderbilt University School of Medicine, Nashville, Tennessee 37232

\begin{abstract}
Elevated levels of endogenous angiotensin can cause hypertensive nephrosclerosis as a result of the potent vasopressor action of the peptide. We have produced by gene targeting mice homozygous for a null mutation in the angiotensinogen gene $\left(\mathrm{Atg}^{-1-}\right)$. Postnatally, $\mathrm{Atg}^{-1-}$ animals show a modest delay in glomerular maturation. Although $\mathrm{Atg}^{-1-}$ animals are hypotensive by 7 wk of age, they develop, by 3 wk of age, pronounced lesions in the renal cortex, similar to those of hypertensive nephrosclerosis. In addition, the papillae of homozygous mutant kidneys are reduced in size. These lesions are accompanied by local up-regulation of PDGF-B and TGF- $\beta 1$ mRNA in the cortex and down-regulation of PDGF-A mRNA in the papilla. The study demonstrates an important requirement for angiotensin in achieving and maintaining the normal morphology of the kidney. The mechanism through which angiotensin maintains the volume homeostasis in mammals includes promotion of the maturational growth of the papilla. (J. Clin. Invest. 1995. 96:2947-2954.) Key words: angiotensinogen $•$ nephrosclerosis - hypotension - platelet-derived growth factor • transforming growth factor
\end{abstract}

\section{Introduction}

Considerable evidence, albeit indirect, has accumulated suggesting that, in addition to its potent vasopressor action, angiotensin II plays an important regulatory role in the development and remodeling of several organs, in particular, the kidney. Indeed, studies in mammals (1-5) have demonstrated that genes for all the components of the renin-angiotensin system (RAS) ${ }^{1}$ are activated during nephrogenesis in the fetal kidney.

Address correspondence to Iekuni Ichikawa, Division of Nephrology, Department of Pediatrics, Vanderbilt University Medical Center, MCN C4204, Nashville, TN 37232. Phone: 615-322-7931; FAX: 615-3227929.

Received for publication 16 March 1995 and accepted in revised form 6 September 1995.

1. Abbreviations used in this paper: ACE, angiotensin converting enzyme; AT1, angiotensin II type-1 receptor; Atg, angiotensinogen gene; ES, embryonic stem; $\mathrm{Neo}^{\mathrm{r}}$, neomycin resistance; RAS, renin-angiotensin system.

J. Clin. Invest.

(C) The American Society for Clinical Investigation, Inc.

0021-9738/95/12/2947/08 \$2.00

Volume 96, December 1995, 2947-2954
Moreover, pharmacological blockade of RAS in maturing young rats results in abnormal kidney morphology (6-8).

While both angiotensin-converting enzyme (ACE) inhibitor and angiotensin type-1 receptor (AT1) antagonists are effective as antihypertensive agents in a variety of hypertensive disorders, they are also uniquely potent in protecting against the end-organ damage which accompanies these disorders $(9,10)$. Thus, in several experimental models, both ACE inhibitor and AT1 antagonist have prevented hypertension, as well as cardiac hypertrophy, vascular wall thickening, glomerular mesangial expansion, and renal interstitial fibrosis (11-19).

To investigate the role of the RAS in vivo, we have utilized gene targeting technology to selectively inactivate the angiotensinogen gene in the mouse. Thus far, two laboratories have studied the phenotype of homozygotes carrying null mutation of this gene $(20,21)$, primarily focusing on the blood pressure control of the mutant. While one study documents "absence of structural abnormalities in major organs" (21), another reports presence of a modest to severe hypertrophy of renal microvasculatures (20).

Our findings support previous indirect evidence for a role of angiotensin in postnatal nephrogenesis. In addition, they indicate an important and unexpected requirement for angiotensin in maintaining the normal postnatal morphology of the kidney.

\section{Methods}

Construction of replacement vector. A replacement type targeting DNA construct was designed to introduce a null-mutation into the mouse angiotensinogen gene (Atg) through homologous recombination. As shown in Fig. $1 a$, a neomycin resistance $\left(\mathrm{Neo}^{r}\right)$ expression cassette (PGK-Neo ${ }^{r}$ ) was used to replace a $1.5-\mathrm{kb}$ HindIII-BamHI fragment, which contains the initiation codon ATG and the entire sequence coding the octapeptide region of angiotensin II. In constructing the replacement vector, the HindIII site present in the genome was eliminated, thus allowing homologous recombination events to be identified by Southern blot analysis.

Generation of angiotensinogen-deficient mice. $65 \mu \mathrm{g}$ of the targeting vector linearized with KpnI was transfected by electroporation, using Gene Pulser (Bio-Rad Laboratories, Hercules, CA), into $1 \times 10^{7}$ E14-1 embryonic stem (ES) cells (kindly provided by Dr. Kitamura, Kyushyu University, Fukuoka, Japan), which had been derived from strain 129/ Ola mouse (22). Transfected clones were selected with G418 (0.4 mg/ ml; Sigma Chemical Co., St. Louis, MO) and gancyclovir ( $2 \mu \mathrm{M}$; gift from Syntex, Palo Alto, CA). Doubly resistant colonies were picked $\sim 9 \mathrm{~d}$ after transfection and grown individually on 96-well plates. At confluency, the cells in each well were frozen and remaining cells were grown further on 96-well plates for genomic Southern blot analysis as described elsewhere (23). ES cells were cultured under standard conditions (24). The cells were grown on irradiated $(5,000$ rads $)$ primary mouse embryonic fibroblasts, prepared from $\mathrm{Neo}^{r}$ transgenic mice. Genomic DNA was purified from each doubly resistant ES clone, di- 
a
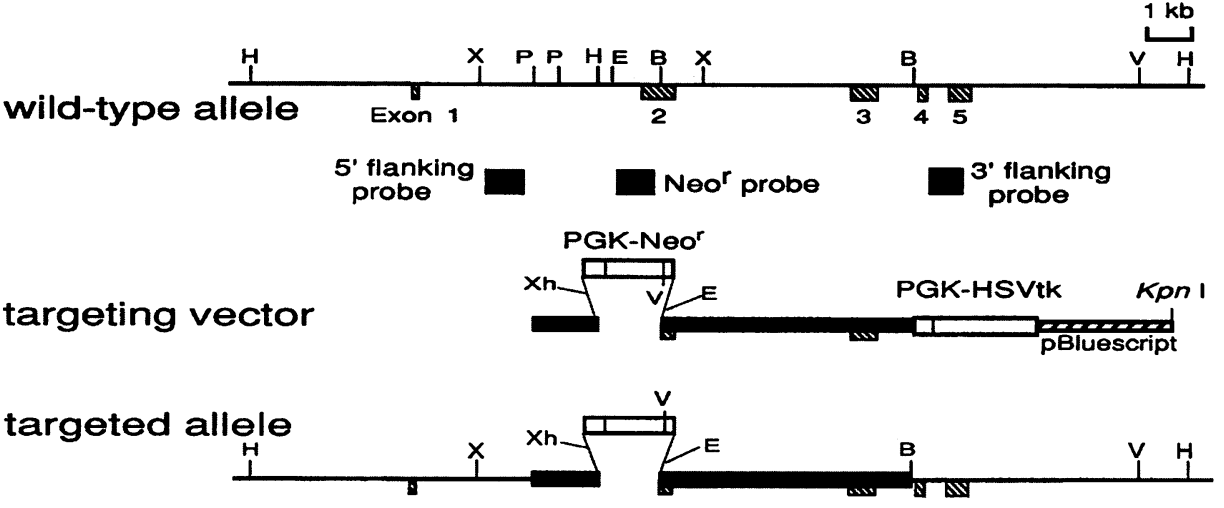

b

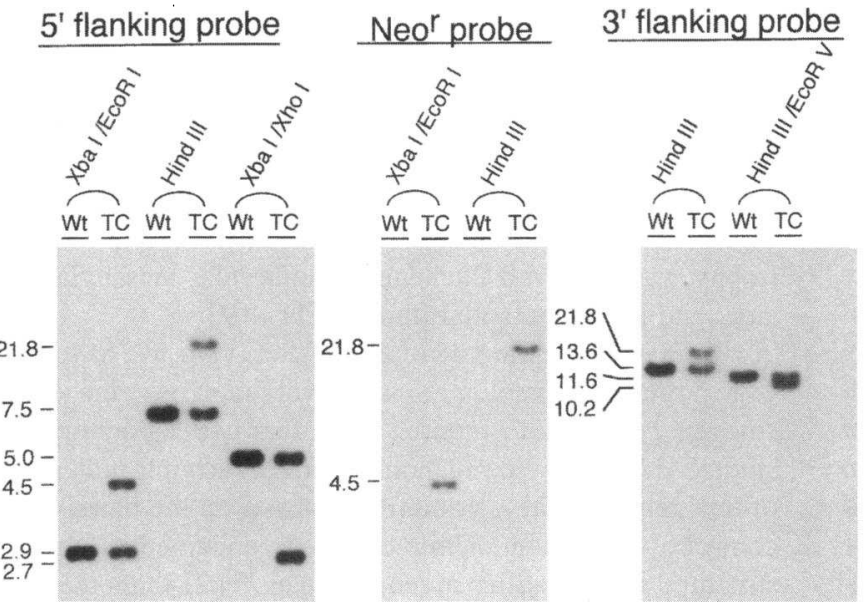

C

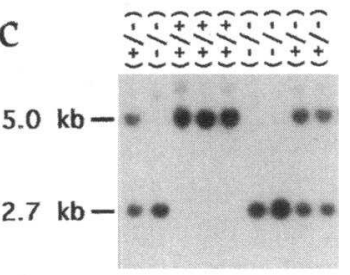

d

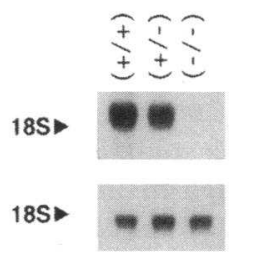

Figure 1. Targeted disruption of the mouse angiotensinogen gene. (a) The structure of the wild-type $129 \mathrm{~Sv} / \mathrm{J}$ angiotensinogen gene is shown on top. The targeted allele shown at the bottom results from replacement of the wild-type allele with the targeting vector. $(b)$ Southern blot analyses of the targeted ES cell DNA. Correct homologous recombination event is confirmed using probes both $5^{\prime}$ and $3^{\prime}$ outside of the targeting vector. Hybridization with the $\mathrm{Neo}^{\mathrm{r}}$ probe verifies that there is only one copy of the targeting vector integrated into chromosomal DNA. (c) Southern blot analysis of $\mathrm{F}_{2}$ offsprings. $3 \mu \mathrm{g}$ of DNA from $\mathrm{F}_{2}$ offspring generated by intercrossing heterozygous $F_{1}$ mice were digested with $\mathrm{XbaI}$ plus XhoI, and probed with the $5^{\prime}$ flanking probe. $(d)$ Northern blot analysis for angiotensinogen mRNA. $10 \mu \mathrm{g}$ of each total RNA from the liver of newborn mice $\left(F_{2}\right.$ generation $)$ were loaded in each lane and probed with a mouse angiotensinogen exon 2 probe (upper row), and a G3PDH probe (lower row) using the same membrane after stripping

the angiotensinogen probe. No angiotensinogen mRNA was detectable even after 3 -d exposure at $-70^{\circ} \mathrm{C}$. $(H, \mathrm{HindIII} ; X, \mathrm{XbaI} ; \mathrm{X} h, \mathrm{XhoI} ; P, \mathrm{PstI}$; $E$, EcoRI; V, EcoRV; B, BamHI; Wt, wild-type ES cells; TC, targeted ES clone).

gested with Xbal plus Xhol, and hybridized with a ${ }^{32} \mathrm{P}$-labeled $0.7 \mathrm{~kb}$ BglII-PstI fragment of angiotensinogen genomic DNA ( $5^{\prime}$ flanking probe in Fig. $1 a$ ), which was external to the $5^{\prime}$ end of the targeting vector. Homologous recombination was observed in $6 / 111$ doubly resistant ES clones. Genomic DNA from each targeted clone was further analyzed using three specific probes, as shown in Fig. $1 b$. One targeted clone was injected into C57BL/6 blastocysts. Six chimeras showed germline transmission of the targeted allele when mated to C57BL/6 females. $\mathrm{F}_{1}$ heterozygotes $\left(\mathrm{Atg}^{+/-}\right)$thus obtained were intercrossed to generate homozygous angiotensinogen-deficient mice of $\mathrm{F}_{2}$ generation. Atg $^{+1+}$, Atg $^{+1-}$, and $\mathrm{Atg}^{-1-}$ mice of $\mathrm{F}_{2}$ generation were then subjected to the analyses described below at birth, 1, 3 and $7 \mathrm{wk}$ of age.

Northern blot analysis for angiotensinogen mRNA. RNA was isolated from the liver within $24 \mathrm{~h}$ after birth using RNAzolB ${ }^{\mathrm{TM}}$ (Tel Test Inc., Friendswood, TX). $10 \mu \mathrm{g}$ of RNA was electrophoresed in $1.0 \%$ agarose gel, transferred to a nylon membrane (Zetabind ${ }^{\mathrm{TM}}$; Cuno Inc. Meriden, CT) and hybridized with ${ }^{32} \mathrm{P}$-labeled exon 2 probe. This probe was prepared by PCR amplification using a forward primer, 5'-CAGAAGCAAATGCACAGATCGGAG-3', and a reverse primer, 5'-CTCACCTTGGAAGTGAACGTAGGT-3', which are based on the DNA sequence of the exon 2 of the mouse angiotensinogen gene (25). The membrane was rehybridized with a human glyceraldehyde 3-phosphate dehydrogenase (G3PDH) cDNA probe (Clontech, Palo Alto, CA) as a control for RNA loading.

Plasma angiotensinogen concentration. Blood samples were collected from 4-wk-old mice into cold tubes in the presence of EDTA $(10 \mathrm{mM})$, and plasma was rapidly separated and kept frozen at $-70^{\circ} \mathrm{C}$. Mouse submandibular renin was purified by the method of Misono et al. (26) and used as a source of mouse renin. $1 \mu \mathrm{l}$ of plasma was incubated with an excess of mouse renin in $\mathrm{pH} 6.0$ maleate buffer, and the generated angiotensin I was measured using a RIANEN Angiotensin I kit (DuPont, Wilmington, DE).

Blood pressure measurement. Blood pressure was measured by tail cuff method using model 179 Blood Pressure Analyzer (IITC Life Science, Woodland Hills, CA). At 7 wk of age, the mice were prewarmed to $29^{\circ} \mathrm{C}$ for $10-15 \mathrm{~min}$ and kept warm during the measurements. Blood pressure was recorded after $5 \mathrm{~d}$ of training sessions. Data were collected only when measurements were reproduced, and three to four data points thus collected were averaged to obtain one value for each animal.

Histological study. Organs were fixed in $4 \%$ buffered paraformaldehyde, embedded in paraffin, and sectioned. Kidney morphology was studied by $3-\mu \mathrm{m}$ thick coronal sections including the papilla stained with periodic acid Schiff. Three animals for each genotype at each age were subjected to analysis. Sex distinction was not made for the histological study. Glomerular density (the number of glomeruli $/ \mathrm{mm}^{2}$ cortex area) and maturity index were calculated for each animal. A mature glomerulus was defined as one with complex capillary branching and flat glomerular visceral epithelial cells. An immature glomerulus was defined as having simple capillary branching and cuboidal glomerular visceral epithelial cells. An intermediate stage glomerulus was characterized by complex branching but with some cuboidal visceral epithelial cells still remaining (Fig. 2, $a-c$ ). Each glomerulus was scored as 1,2 , and 3 to reflect the immature, intermediate, and mature state of the glomerulus, respectively. The maturity index was determined for each animal as an average of the score of all glomeruli present in the section examined for bilateral kidneys. To assess maturation in different areas of the cortex, the cortex from newborn and 1-wk-old mice was arbitrarily divided into two zones, i.e., an inner zone, half of the thickness of the cortex, and an outer zone with the remaining half thickness. The parameters were calculated for each zone of the cortex. The cortical 


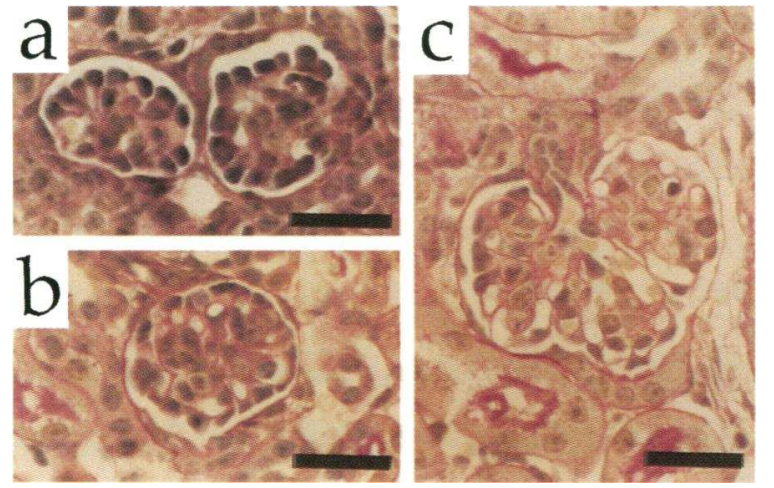

Figure 2. Scoring glomerular maturity. Each glomerulus was scored according to the degree of maturity: (a) Immature glomeruli (score 1) with simple capillary branching outlined by cuboidal epithelial cells; (b) intermediate glomeruli (score 2) with some cuboidal epithelial cells still remaining; $(c)$ mature glomerulus with complex capillary network, open lumens and flattened epithelial cells (score 3 ). PAS stain, $\times 480$. The length of the bar in each figure represents $21 \mu \mathrm{m}$.

area and average glomerular tuft area were measured planimetrically using the Micro-Plan II $^{\mathrm{TM}}$ image analysis system (Donsanto, Natick, MA). All the semiquantitative parameters were obtained by an independent pathologist without any information about the nature of each specimen.

Immunohistochemistry for renin. Kidneys from 3-wk-old mice were stained for renin, using the ImmunoPure ${ }^{\mathrm{TM}} \mathrm{ABC}$ Peroxidase Staining Kit (Pierce, Rockford, IL), following the manufacturer's instructions. An anti-rat renin goat antibody raised in T. Inagami's laboratory was used as a primary antibody.

In situ hybridization study for PDGF-A, PDGF-B, and TGF- $\beta 1$. Mouse PDGF-A, PDGF-B cDNA clones (references 27, 28; gift from Dr. Stiles of the Dana Faber Cancer Institute, Boston, MA), and mouse TGF- $\beta 1$ cDNA clone (reference 29 , gift from Dr. H. Moses, Vanderbilt Medical School, Nashville, TN) were used as templates to synthesize ${ }^{35} \mathrm{~S}$-labeled antisense and sense cRNA probes. These probes cover 0.8 $\mathrm{kb}$ (1-906 bp), $0.8 \mathrm{~kb}$ (entire protein coding sequence), and $1.0 \mathrm{~kb}$ (421-1395 bp), respectively, of mouse PDGF-A, PDGF-B, and TGF$\beta 1$ cDNA. The protocol for in situ hybridization used in the current study is essentially identical to that used previously $(1,30)$. Briefly, the 3- $\mu \mathrm{m}$ sections were treated with $20 \mu \mathrm{g} / \mathrm{ml}$ proteinase $\mathrm{K}$ and acetic anhydride successively, dehydrated in $30-100 \%$ ethanol and air-dried. $60 \mathrm{ml}$ of hybridization mixture containing $2 \times 10^{4} \mathrm{cpm} / \mathrm{ml}$ of ${ }^{35} \mathrm{~S}$ labeled cRNA probe, $50 \%$ deionized formamide, $10 \%$ dextran sulfate, $8 \mathrm{mM}$ DTT, $0.2 \mathrm{mg} / \mathrm{ml}$ tRNA and $1 \times$ salts $(300 \mathrm{mM} \mathrm{NaCl}, 10 \mathrm{mM}$ Tris- $\mathrm{HCl}, 5 \mathrm{mM}$ EDTA, $0.02 \%$ polyvinylpyrolidone, $0.02 \%$ Ficoll, and $0.02 \% \mathrm{BSA}$ ) were overlaid on the specimens and incubated for $15 \mathrm{~h}$ at $50^{\circ} \mathrm{C}$ in a humidified chamber. The specimens were washed in $50 \%$ deionized formamide, $2 \times \mathrm{SSC}, 100 \mathrm{mM}$ DTT at $65^{\circ} \mathrm{C}$ for $20 \mathrm{~min}$, followed by $20 \mu \mathrm{g} / \mathrm{ml} \mathrm{RNase}$ at $37^{\circ} \mathrm{C}$ for $30 \mathrm{~min}$. They were further washed in $2 \times \mathrm{SSC}$, followed by $0.1 \times \mathrm{SSC}$ at $65^{\circ} \mathrm{C}$, dehydrated in 30-100\% ethanol with $0.3 \mathrm{M}$ ammonium acetate, and air-dried. The slides were dipped in photographic emulsion (Ilford K-5 emulsion; Ilford Ltd., Essex, United Kingdom) and exposed at $4^{\circ} \mathrm{C}$ for 7-10 d. The sections were developed with D-19 developer (Eastman Kodak Co., Rochester, NY) and counterstained with $0.02 \%$ toluidine blue.

\section{Results}

As shown in Fig. $1 a$ and $b$, gene targeting in embryonic stem cells was used to delete exon 2 of the mouse Atg, which encodes the initiator ATG and the entire sequence of the octapeptide angiotensin II. A total of $148 \mathrm{~F}_{2}$ offspring were genotyped by
Southern blot analysis of tail DNA obtained within 3 wk of birth. Of these, $42(28.4 \%)$ were wild-type $\left(\mathrm{Atg}^{+/+}\right), 78$ $(52.7 \%)$ were heterozygous $\left(\mathrm{Atg}^{+/-}\right)$, and $28(18.9 \%)$ were homozygous $\left(\mathrm{Atg}^{-1-}\right)$ for the targeted null mutation, indicating that there was little or no loss of $\mathrm{Atg}^{-1-}$ animals in utero. Typical Southern blot patterns are shown in Fig. $1 c$.

To confirm that the mutation had indeed disrupted the angiotensinogen gene, homozygous mutant animals were assayed for both RNA and protein. Northern blot analysis of RNA prepared from the liver of $\mathrm{Atg}^{+1+}, \mathrm{Atg}^{+/-}$, and $\mathrm{Atg}^{-1-} \mathrm{F}_{2}$ newborn mice failed to detect angiotensinogen mRNA in $\mathrm{Atg}^{-1-}$ mice (Fig. 1 $d$ ). Plasma angiotensinogen concentration, determined by the amount of angiotensinogen I generated after cleavage by mouse renin, was, on average, $0.55 \pm 0.11 \mu \mathrm{g}$ angiotensin $\mathrm{I} / \mathrm{ml}$ in Atg $^{+1+}$ mice, $0.26 \pm 0.03 \mu \mathrm{g}$ angiotensin $\mathrm{I} / \mathrm{ml}$ in $\mathrm{Atg}^{+/-}$mice, and not detectable in $\mathrm{Atg}^{-1-}$ mice (mean $\pm \mathrm{SD}, n=4$ for each determination). Systolic pressure measured at 7-8 wk of age averaged $118 \mathrm{mmHg}$ in $\mathrm{Atg}^{+/+}$mice, $97 \mathrm{mmHg}$ in $\mathrm{Atg}^{+/-}$mice, and $77 \mathrm{mmHg}$ in $\mathrm{Atg}^{-1-}$ mice. These values are comparable to those for Atg-targeted mice recently reported from other laboratories $(20,21)$.

No gross anatomical deformity was recognized at birth in $\mathrm{Atg}^{+1+}, \mathrm{Atg}^{+/-}$, and $\mathrm{Atg}^{-1-}$ mice born from $\mathrm{Atg}^{+1-}$ mothers. A tendency for delayed weight gain in $\mathrm{Atg}^{-1-}$ mice was seen at $1 \mathrm{wk}$ of age (Table I). At $3 \mathrm{wk}$, delayed weight gain in Atg $^{-1-}$ mice became more apparent. Atg $^{-1-}$ mice had on average a lower liver weight than the other genotypes. Heart weight at $3 \mathrm{wk}$ of age was, on average, lowest in Atg $^{-1-}$ mice and

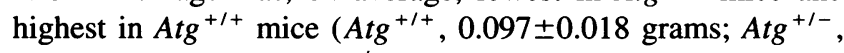
$0.082 \pm 0.010$ grams; Atg $^{-1-}, 0.071 \pm 0.004$ grams; mean $\pm S D$, $n=3,14$, and 3, respectively), although the difference did not reach statistical significance.

The histology of kidneys was investigated at birth and also at 1 and 3 wk postnatally. Previous studies had shown that treatment of young rats with inhibitors of ACE and antagonists of AT1 led to a delay in glomerular maturation, suggesting a role of the renin-angiotensin system in nephron maturation. We therefore scored glomeruli for maturation both at the time of birth and postnatally (Table II) using the criteria outlined in Fig. 2. At birth, there were more immature glomeruli in the inner cortex, where glomerular maturation occurs first, in $\mathrm{Atg}^{-1-}$ mice (maturity index: $1.74 \pm 0.15$ ) than in either ${ }^{+/+}$ $(2.13 \pm 0.23)$ or $^{+1-}(2.27 \pm 0.39$, mean $\pm S D, n=3$ for each genotype) mice, although the difference did not reach statistical significance. The difference in glomerular maturity was more pronounced by $1 \mathrm{wk}$ of age and reached statistical significance. At this time, the maturity index in the inner cortex averaged

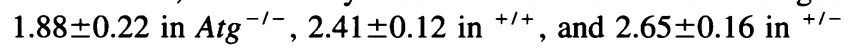
mice. Similar to findings at birth, however, no significant difference was observed in maturity in the outer cortex, where maturation occurs last. At $3 \mathrm{wk}$ of age, the majority of the glomeruli in $\mathrm{Atg}^{-1-}$ mice were mature, and there was no difference in the maturity index among the three genotypes (Table II). We also evaluated the density as well as the size of glomeruli. We found little difference in glomerular density at birth or at 1-3 wk. Similarly, no major difference was detected in mean glomerular tuft area at birth or at $1 \mathrm{wk}$ of age among genotypes. However, at $3 \mathrm{wk}$, glomerular tuft area was substantially and significantly smaller in $\mathrm{Atg}^{-1-}$ mice $\left(1.63 \pm 0.40 \times 10^{-3} \mathrm{~mm}^{2}\right)$ than $\mathrm{Atg}^{+1-}$ $\left(2.34 \pm 0.29 \times 10^{-3} \mathrm{~mm}^{2}\right)$ and ${ }^{+1+}\left(2.18 \pm 0.42 \times 10^{-3} \mathrm{~mm}^{2}\right.$, mean $\pm \mathrm{SD}, n=3$ for each genotype) mice.

The $\mathrm{Atg}^{-1-}$ mice demonstrated other renal structural abnor- 


\begin{tabular}{|c|c|c|c|c|c|c|}
\hline \multirow[b]{2}{*}{ Genotype } & \multicolumn{3}{|c|}{$1 \mathrm{wk}$} & \multicolumn{3}{|c|}{2 wk } \\
\hline & $(+/+)$ & $(+/-)$ & $(-1-)$ & $(+1+)$ & $(+1-)$ & $(-1-)$ \\
\hline$n$ & 3 & 3 & 3 & 3 & 14 & 3 \\
\hline Body weight (grams) & $5.3 \pm 0.6$ & $5.4 \pm 0.3$ & $3.8 \pm 0.9$ & $14.8 \pm 1.4$ & $15.0 \pm 2.0$ & $12.1 \pm 0.8^{*}$ \\
\hline Kidney weight (grams) & $0.032 \pm 0.006$ & $0.030 \pm 0.004$ & $0.028 \pm 0.004$ & $0.093 \pm 0.009$ & $0.094 \pm 0.014$ & $0.093 \pm 0.011$ \\
\hline Percentage of body weight & $0.60 \pm 0.04$ & $0.56 \pm 0.10$ & $0.75 \pm 0.09$ & $0.63 \pm 0.01$ & $0.63 \pm 0.05$ & $0.77 \pm 0.04 *$ \\
\hline
\end{tabular}

Mean \pm SD. ${ }^{*} P<0.05$ vs $(+/+)$ by $t$ test, following ANOVA.

malities. In 1-wk-old $\mathrm{Atg}^{-1-}$ mice, mild tubular dilatation without interstitial fibrosis was present in the outer medulla. Mild thickening of arteriolar walls was seen in cortical vessels in some specimens. More profound and distinctive pathologic lesions were present at $3 \mathrm{wk}$ of age in $\mathrm{Atg}^{-1-}$ mice (Fig. 3). The pelvic space was enlarged in $\mathrm{Atg}^{-1-}$ mice, due to atrophic (or hypoplastic) papillae. Prominent medial hyperplasia was present in the interlobular arteries and afferent arterioles, whereas the main branches of the renal artery remained intact. Mesangial expansion was present around the stalk near the vascular pole. Dilated collecting ducts in the outer medulla also became more evident in $\mathrm{Atg}^{-1-}$ mice at $3 \mathrm{wk}$ of age. Mild but distinct interstitial fibrosis was also seen in Atg $^{-1-}$ mice $3 \mathrm{wk}$ of age, but not in $\mathrm{Atg}^{+1+}$ or $\mathrm{Atg}^{+/-}$mice.

To examine whether the observed vascular wall hypertrophy is a result of proliferation of juxtaglomerular (JG) cells, or a consequence of hyperplasia/hypertrophy of the arterial wall per se, kidneys from 3-wk-old $\mathrm{Atg}^{-1-}$ mice were analyzed immunohistochemically for renin expression. Renin was demonstrable along the afferent arterioles and interlobular arteries which showed prominent medial hyperplasia. However, not all the cells in the medial layer of small arteries were positive for renin staining. Furthermore, no renin staining was observed in the mesangial area. In the kidneys from $\mathrm{Atg}^{+1-}$ and $\mathrm{Atg}^{+/+}$mice, the pattern of renin staining was localized to the afferent arterioles immediately adjacent to the glomerulus but not in the arteriole distant from the glomerulus.

To identify potential growth factors underlying the proliferative lesions present in the $\mathrm{Atg}^{-1-}$ mouse kidneys, we assessed tissue mRNA expression of several pertinent growth factors. In kidneys of 3-wk-old $\mathrm{Atg}^{-1-}$ mice, remarkably intense signals for PDGF-B chain mRNA were seen in the dilated tubules in the outer medulla (Fig. $4 a$ ). PDGF-B chain signal was also present at high levels in the endothelial layer of the thickened arterioles and arteries, but relatively less in the medial layer where the hyperplasia was prominent (Fig. 4 b). Atg $^{+/+}$(Fig. $4 d$ ) and $\mathrm{Atg}^{+/-}$mice showed only weak signals for the PDGF$B$ chain in proximal tubules and vessels in the cortex. Northern blot analysis revealed identical PDGF-B chain mRNA signal in the whole kidney of $\mathrm{Atg}^{+1+}$ and $\mathrm{Atg}^{-1-}$ mice (not shown). Therefore, the intense PDGF-B signals observed in the hypertrophic vascular walls and dilated tubules in $\mathrm{Atg}^{-1-}$ mice are evidently highly localized. As shown in Fig. $4 e-f$, enhanced levels of TGF- $\beta 1$ mRNA was also present in 3-wk-old $\mathrm{Atg}^{-1-}$ mice. In contrast to the localization of PDGF-B, the signals were present in areas of interstitial fibrosis surrounding dilated tubules and thickened arteries. Atg $^{+/+}$(Fig. $4 \mathrm{~g}$ ) and $\mathrm{Atg}^{+/-}$mice showed no appreciable signals for TGF- $\beta 1$ in the cortex and very weak homogeneous signals in the inner medulla. When hybridized with sense RNA probes for PDGF-B and TGF- $\beta 1$ mRNA, only weak nonspecific background was present (not shown). In contrast to the above-described expression patterns of PDGF-B and TGF- $\beta 1 \mathrm{mRNA}$ that are intensified locally at the lesions of $\mathrm{Atg}^{-1-}$ mice, PDGF-A mRNA was found to be highly expressed in the papilla of wild-type mice (Fig. $4 i$ ), and most strikingly, absent in the atrophic (or hypoplastic) papilla of $\mathrm{Atg}^{-1-}$ mice (Fig. $4 \mathrm{~h}$ ).

To investigate whether angiotensinogen of maternal origin plays an important role in the rescue of embryonic nephrogenesis in utero, Atg $^{-1-}$ female and Atg $^{+/-}$male mice $\left(\mathrm{F}_{2}\right.$ generation) were crossed, and their offspring were killed at birth for morphological analysis. Of the 11 offspring $^{2}, 7$ were genotyped

2. These are the products of mating two pairs of $\mathrm{F}_{2}\left(\mathrm{Atg}^{-1-}\right)$ females and $\mathrm{F}_{2}\left(\mathrm{Atg}^{+/-}\right)$males, which resulted in conception and delivery of normal number of pups (seven for each litter). Three pups were consumed by the mothers shortly after birth, therefore, not available for study. The remaining pups were killed within $24 \mathrm{~h}$ to generate data cited in the text.

Table II. Glomerular Maturity Index

\begin{tabular}{|c|c|c|c|c|c|c|c|c|c|}
\hline \multirow[b]{2}{*}{ Genotype } & \multicolumn{3}{|c|}{ At birth } & \multicolumn{3}{|c|}{$1 \mathrm{wk}$} & \multicolumn{3}{|c|}{$3 w k$} \\
\hline & $(+/+)$ & $(+/-)$ & $(-1-)$ & $(+/+)$ & $(+/-)$ & $(-1-)$ & $(+1+)$ & $(+/-)$ & $(-1-)$ \\
\hline$n$ & 3 & 3 & 3 & 3 & 3 & 3 & 3 & 3 & 3 \\
\hline Total cortex & $1.66 \pm 0.21$ & $1.76 \pm 0.24$ & $1.43 \pm 0.08$ & $1.79 \pm 0.13$ & $1.78 \pm 0.28$ & $1.38 \pm 0.15^{*}$ & $2.98 \pm 0.03$ & $2.99 \pm 0.01$ & $2.93 \pm 0.03$ \\
\hline Outer cortex & $1.21 \pm 0.03$ & $1.20 \pm 0.10$ & $1.17 \pm 0.03$ & $1.55 \pm 0.07$ & $1.53 \pm 0.32$ & $1.22 \pm 0.14$ & n.d. & n.d. & n.d. \\
\hline Inner cortex & $2.13 \pm 0.23$ & $2.27 \pm 0.39$ & $1.74 \pm 0.015$ & $2.41 \pm 0.12$ & $2.65 \pm 0.16$ & $1.88 \pm 0.22 *$ & n.d. & n.d. & n.d. \\
\hline
\end{tabular}

Mean \pm SD. ${ }^{*} P<0.05$ vs $(+/+)$ by $t$ test; n.d., not done. 

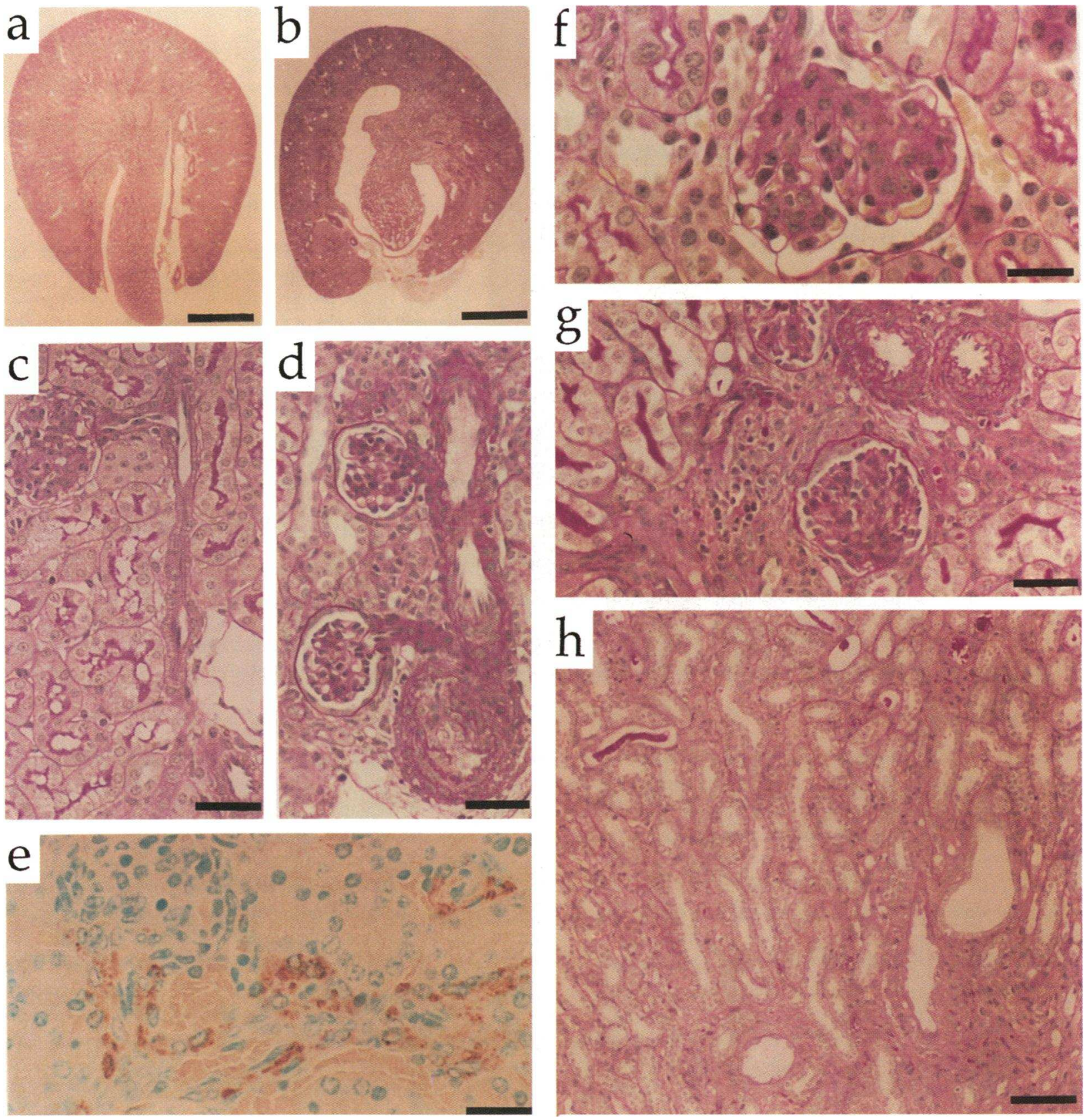

Figure 3. Morphology of the kidney of 3-wk-old angiotensinogen-deficient mice. $(a)$ and $(c)$ are from $\operatorname{Atg}^{+/+}$mice, and $(b),(d-h)$ are from $\mathrm{Atg}^{-1-}$ mice. Coronal sections of the kidneys from $\mathrm{Atg}^{+1+}(a)$ and $\mathrm{Atg}^{-1-}(b)$ mice at $3 \mathrm{wk}$ of age. Pelvic dilatation was present in $\mathrm{Atg}^{-1-}$ mice, with atrophic papilla compared to $\mathrm{Atg}^{+/+}$mice. (c) Normal arterioles in $\mathrm{Atg}^{+1+}$ mice. (d) Medial hyperplasia of interlobular artery and afferent arterioles. $(e)$ Immunoreactivity to renin is demonstrated along the interlobular artery and afferent arteriole. $(f)$ Glomerulus showing axial mesangial expansion. $(g)$ Patchy fibrosis and mononuclear cell infiltrate in the interstitium. $(h)$ Dilated tubules in the outer medulla. Interstitial fibrosis is also seen around the dilated tubules. (PAS stain; $a$ and $b, \times 10 ; c$ and $d, \times 300 ; e$ and $f \times 600 ; g, \times 300 ; h, \times 150$ ) The length of the bars represents 1 $\mathrm{mm}(a$ and $b), 33 \mu \mathrm{m}(c, d$, and $g), 17 \mu \mathrm{m}(e$ and $f)$, and $67 \mu \mathrm{m}(h)$, respectively.

as $\mathrm{Atg}^{+/-}$, and 4 were $\mathrm{Atg}^{-1-}$. No gross anatomical abnormality was found in $\mathrm{Atg}^{+/-}$or $\mathrm{Atg}^{-1-}$ newborn mice from the $\mathrm{Atg}^{-1-}$ mothers. Light microscopic findings of the kidneys were qualitatively comparable to the newborn mice from $\mathrm{Atg}^{+/-}$mothers. Semiquantitative analysis revealed that, unlike the $\mathrm{Atg}^{+/-}$and $\mathrm{Atg}^{-1-}$ mice from the $\mathrm{Atg}^{+1-}$ mother, the $\mathrm{Atg}^{+1-}$ and $\mathrm{Atg}^{-1-}$ mice from the $\mathrm{Atg}^{-1-}$ mother had comparable values of maturity index $\left(\mathrm{Atg}^{+1-}, 1.50 ; \mathrm{Atg}^{-1-}, 1.51\right)$ at birth. These values were similar to those of newborn Atg $^{-1-}$ mice from the $\mathrm{Atg}^{+1-}$ mother, and lower than those of $\mathrm{Atg}^{+/-}$mice from the Atg $^{+/-}$mother, indicating that maternal angiotensinogen does not contribute to intrauterine renal development.

\section{Discussion}

Previous experimental attempts to identify the role of the reninangiotensin system in mammalian development were limited by methodological problems. For example, the specificity and 

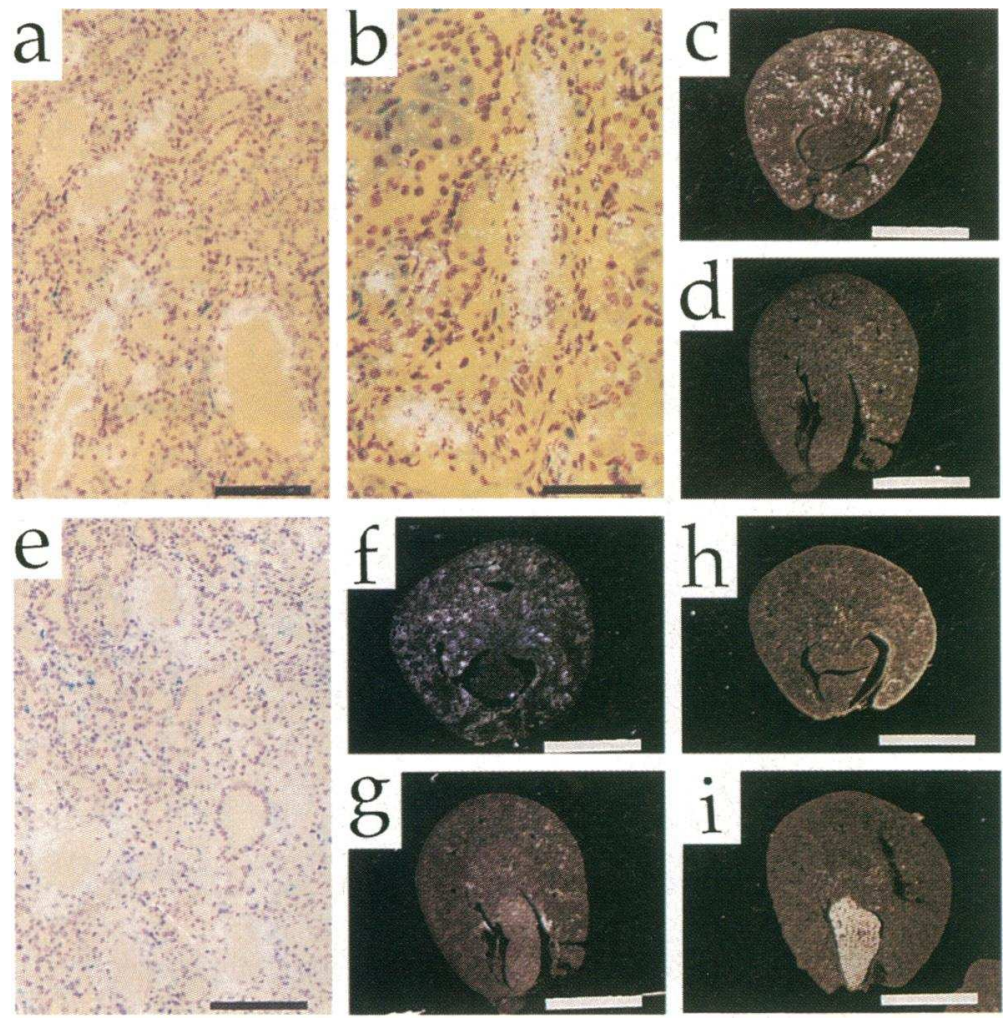

Figure 4. In situ hybridization for PDGF-A, PDGF-B, and TGF- $\beta 1$ mRNA in the kidney of $\operatorname{Atg}^{-1-}$ and $\operatorname{Atg}^{+1+}$ mice at 3 wk of age. Intense signals for PDGF-B mRNA on $(a)$ the epithelial cells of the dilated tubules and $(b)$ the endothelial cells of small artery with medial hyperplasia in $\mathrm{Atg}^{-1-}$ mice. Dark field photographs in lower magnification show the difference in the distribution of PDGF-B mRNA expression in the kidneys of $(c) \mathrm{Atg}^{-1-}$ and (d) $\mathrm{Atg}^{+1+}$ mice. (e) Distinct signals for TGF- $\beta 1 \mathrm{mRNA}$ are present on the interstitial cells in the fibrotic area around the dilated tubules in a $\mathrm{Atg}^{-1-}$ mouse. Dark field photographs in lower magnification show a different intrarenal expression pattern of TGF- $\beta 1$ mRNA in $(f) \mathrm{Atg}^{-1-}$ and $(g) \mathrm{Atg}^{+/+}$mice. $(h)$ The papilla of the $\mathrm{Atg}^{-1-}$ is lacking the intense signals for PDGF-A mRNA. ( $i$ ) Intense expression of PDGF-A mRNA in the papilla of the $\mathrm{Atg}^{+/+}$mouse. ( $a$ and $e, \times 100 ; b$, $\times 200 ; c, d, f, g, h$, and $i, \times 4)$ The length of the bars represents $0.1 \mathrm{~mm}(a$ and $e), 0.05 \mathrm{~mm}(b)$, and $2.5 \mathrm{~mm}$ $(c, d, f, g, h$, and $i$ ), respectively. potency of commonly used pharmacological RAS inhibitors were difficult to verify in vivo. Moreover, lack of an appropriate route of administration of inhibitors precluded studies at early developmental stages, i.e., preweaning or embryonic period. When pharmacological inhibition of RAS was found to attenuate the maturational increase in nephron size at late developmental stages, the observation was extrapolated to indicate that RAS may also regulate the early maturational growth of nephrons (6-8). Our observations in angiotensinogen null mutant mice confirm these previous findings in rats during the later phase of development. Thus, 3-wk-old $\mathrm{Atg}^{-1-}$ mice were found to have significantly smaller glomerular tuft area when compared to control animals. Our studies further demonstrate that, at earlier stages, RAS does affect the morphological maturity of the glomerulus. Developmental delay was noticeable at birth and became more accentuated at $1 \mathrm{wk}$ in $\mathrm{Atg}^{-1-}$ mice since glomeruli with cuboidal epithelial cells and simple capillary configuration were present in greater numbers when compared to control animals.

In addition to a direct effect of angiotensin that acts through its receptor within the glomerulus, hypotension, if present at early stages of development, in and of itself may be responsible for the glomerular abnormality observed in our study. Also, some impairment in fluid homeostasis, as evidenced by the poor weight gain in $\mathrm{Atg}^{-1-}$ mice could underlie the manifestation of the abnormality.

Since the limited number of $F_{2}$ mice examined in our study could carry heterogeneous genetic background, our statistical analysis on quantitative morphologic data may not be sufficiently sensitive to detect subtle, but biologically important, differences. By the same token, some of the quantitative difference described between $\mathrm{Atg}^{-1-}$ vs $\mathrm{Atg}^{+/-}$and $\mathrm{Atg}^{+/+}$may be attributed to a skew in the genetic background among the small populations of animals studied. In this regard, to identify the nature of the influence of the two types of genetic background, i.e., those of $129 / \mathrm{Sv}$ and $\mathrm{C} 57 \mathrm{BL} / 6$, that make up $\mathrm{F}_{2}$ was ascertained for two of the key quantitative parameters assessed in $\mathrm{F}_{2}$. Thus, pups from two litters each of $129 / \mathrm{Sv}(n=6)$ and C57BL/6 $(n=7)$ were examined at $1 \mathrm{wk}$ of age for glomerular maturity index and glomerular tuft area. Glomerular maturity index (inner cortex) averaged $2.83 \pm 0.08$ and $2.80 \pm 0.15$ for $129 / \mathrm{Sv}$ and C57BL/6, respectively; and glomerular tuft area $1.25 \pm 0.15 \times 10^{-3} \mathrm{~mm}^{2}$ and $1.27 \pm 0.13 \times 10^{-3} \mathrm{~mm}^{2}$, respectively ${ }^{3}$. In all likelihood, the observed difference in glomerular maturation and growth between targeted and wild-type $F_{2}$ animals is attributed to the deletion of Atg in targeted mice per se, and not to a potential skew in genetic background among these animals.

Our results also indicate, however, that RAS plays little regulatory role at the onset of nephrogenesis. Thus, the nephron density was unaffected throughout the stages examined. Moreover, at birth and $1 \mathrm{wk}$, the glomeruli with significant maturational delay are found primarily in the inner zone of the cortex, where glomerular maturation is most advanced. Furthermore, the degree of maturational delay is relatively less at birth than at $1 \mathrm{wk}$. This lack of major delay in nephron maturation in the $\mathrm{Atg}^{-1-}$ newborn pups is not the result of rescue by angiotensino-

3. These are the two quantitative parameters for which Atg $^{-1-}$ mice were found to be significantly different from $\mathrm{Atg}^{+1+}$ or $\mathrm{Atg}^{+/-}$mice. Numerically, the average maturity index values in these two wild-type strains are higher than any of the $F_{2}$ animals. This appears to reflect largely the fact that the control studies on pure 129/Sv and C57BL/6 were done separately by a new coinvestigator ( $S$. Okubo) after the completion of all of the studies on $\mathrm{F}_{2}$ animals. 
gen or angiotensin of maternal origin during gestation since there is comparable nephron maturity in $\mathrm{Atg}^{-1-}$ neonates born from $\mathrm{Atg}^{+/-}$and those from $\mathrm{Atg}^{-1-}$ mothers. Overall, our current observations that only the late-stage nephrogenesis is affected in $\mathrm{Atg}^{-1-}$ mice are consistent with the findings from earlier gene expression studies that the gene transcript of angiotensin type-1 receptor, which transduces virtually all the known actions of angiotensin II, appears long after specific mesenchymal cells have committed to initiating nephrogenesis (1).

Although the studies suggest an effect, albeit modest, of angiotensinogen deficiency on nephrogenesis, the most striking pathological changes develop in the kidney after birth. Most remarkable was wall thickening of the interlobular arteries and afferent arterioles due to medial hypertrophy and/or hyperplasia, a finding already described by Kim et al. (20). Abnormal reduplication of the internal elastic lamina was also frequently observed. In contrast to these remarkable abnormalities in the renal microvasculature, no appreciable abnormality was found in the cardiac muscle or coronary arterial walls in the same $\mathrm{Atg}^{-1-}$ mice (data not shown). The microvascular lesions that are prominent in the kidney are remarkably reminiscent of lesions typical of nephrosclerosis, commonly referred to as hypertensive vascular remodeling (31). Hyperplasia of the juxtaglomerular cell, which is also often seen in nephrosclerosis, was also prominent in the $\mathrm{Atg}^{-1-}$ mice. Moreover, renin-positive cells extended into a part of the thickened wall of arteries and arterioles. These observations duplicate earlier observations by Gomez et al. $(32,33)$ in which pharmacological inhibition of angiotensin in rats results in "recruitment of renin-positive cells"'. Of interest, in the $\mathrm{Atg}^{-1-}$ mice, the thickened afferent arteriolar wall was made up of both renin-positive and negative cells, indicating that not only juxtaglomerular cells, but also vascular smooth muscle cells are undergoing a profound proliferation. Dilatation of tubules, expansion of mesangial cells, interstitial fibrosis, and cellular infiltration, frequently associated with nephrosclerosis and other chronic renal lesions, were also demonstrated in $\mathrm{Atg}^{-1-}$ mice.

The renal vascular lesions present in $\mathrm{Atg}^{-1-}$ mice resemble hypertensive nephrosclerosis on another level. Langille showed existence of endothelium-dependent mechanisms operating in the vascular-remodeling process (34). PDGF, which is produced by several cell types, including endothelial cells (35), was proposed as the candidate growth factor involved in this process (31). In our study, enhanced PDGF-B mRNA expression was found in the endothelial cells of the thickened arteries and arterioles of $\mathrm{Atg}^{-1-}$ mice, suggesting that the renal vascular lesions found in our $\mathrm{Atg}^{-1-}$ mice are driven, at least in part, by the same mechanism as hypertensive nephrosclerosis. Enhanced expression of PDGF-B mRNA was demonstrated in the epithelial cells of the dilated tubules, as was TGF- $\beta 1$ mRNA expression in the interstitial cells surrounding the dilated tubule and thickened arteries, where fibrosis and mononuclear cell infiltrate are present. Previous in vitro and in vivo studies demonstrated that angiotensin II can upregulate PDGF and TGF- $\beta$ in vascular smooth muscle and other cells $(27,36-38)$. The present gene targeting study reveals that the absence of angiotensin II can also lead to the upregulation of PDGF-B and TGF- $\beta$. It appears, therefore, that normal level of angiotensin II is essential for the maintenance of renal vascular structure and for the regulation of various growth factor activities. The current observations are also consistent with our most recent observations on the kidneys of growth hormone transgenic mice, in which attempts to allevi- ate development of glomerular sclerosis with ACE inhibitor and AT1 receptor antagonist led to the surprising induction of hypertrophic renal arteriolar lesions (39).

Apart from the several new insights into the biological function of RAS that have been discussed, the current gene targeting study has brought up a new question, i.e., how does suppression of angiotensin lead to activation of some growth factors. Activation of other vasopressor systems, for example the sympathetic nervous system and/or vasopressin, which can be activated in response to lowered blood pressure in $\mathrm{Atg}^{-1-}$ mice, may mediate this effect. Given our observation that renal renin is abnormally activated in $\mathrm{Atg}^{-1-}$ mice, the possibility exists that this elevated renin may exert a significant biological activity that is linked to cell proliferation. This notion revives an old, unresolved issue, namely that there may exist biologically important alternative renin substrate (s) (i.e., other than angiotensinogen), which can be metabolized by renin to yield potent proliferative substance ( $\mathrm{s}$ ).

Finally, the current gene-targeting study revealed another unexpected phenomenon in $\mathrm{Atg}^{-1-}$ mice, namely the appearance of atrophic (or hypoplastic) renal papillae, which is essential for the establishment of efficient counter current and counter exchanger systems. Of great interest, this phenomenon was accompanied by down-regulation of PDGF-A mRNA which is abundant in the growing papilla of wild-type animals. It therefore remains to be investigated whether this represents the absence of the particular cell type normally expressing PDGF-A, or the suppression of PDGF-A gene transcription in cells in which it is normally expressed. Regardless of the causal linkage between the observed absence of PDGF-A expression and the presence of atrophy (or hypoplasia) in the papilla of $\mathrm{Atg}^{-1-}$ mice, the present study has revealed an important role for RAS in the overall volume-conserving homeostatic mechanism. Thus, in addition to effect on reducing renal blood flow, and stimulating renal tubule salt transport and, centrally, water drinking drive, RAS is required for the normal maturational growth of the papilla.

\section{Acknowledgments}

The authors thank Ms. Tracy Moore-Jarrett for technical assistance and Ms. Mary Beehan for editorial assistance.

This work was supported by National Institute of Health grants DK44757 and DK-37868. Dr. Agnes Fogo is a recipient of an Established Investigator Award from the American Heart Association. Dr. Patricia A. Labosky is an Associate and Brigid L. M. Hogan an Investigator of the Howard Hughes Medical Institute.

\section{References}

1. Kakuchi, J., T. Ichiki, S. Kiyama, B. L. M. Hogan, A. Fogo, T. Inagami, and I. Ichikawa. 1995. Developmental expression of renal angiotensin II receptor genes in the mouse. Kidney Int. 47:140-147.

2. Richoux, J. P., S. Amsaguine, G. Grignon, J. Bouhnik, J. Menard, and P. Corvol. 1987. Earliest renin containing cell differentiation during ontogenesis in the rat. Histochemistry. 88:41-46.

3. Gomez, R. A., C. Pupilli, and A. D. Everett. 1991. Molecular and cellular aspects of renin during kidney ontogeny. Pediatr. Nephrol. 5:80-87.

4. Wallace, K. B., M. D. Bailie, and J. B. Hook. 1979. Development of angiotensin-converting enzyme in fetal rat lungs. Am. J. Physiol. 236:R57-R60.

5. Mounier, F., N. Hinglais, M. Sich, F. Gros, M. Lacoste, Y. Deris, F. AlhenkGelas, and M. C. Gubler. 1987. Ontogenesis of angiotensin-I converting enzyme in human kidney. Kidney Int. 32:684-690.

6. Fogo, A., Y. Yoshida, A. Yared, and I. Ichikawa. 1990. Importance of angiogenic action of angiotensin II in the glomerular growth of maturing kidneys. Kidney Int. 38:1068-1074. 
7. Tufro-McReddie, A., D. W. Johns, K. M. Geary, H. Dagli, A. D. Everett, R. L. Chevalier, R. M. Carey, and R. A. Gomez. 1994. Angiotensin II type 1 receptor: role in renal growth and gene expression during normal development. Am. J. Physiol. 266:F911-F918.

8. Friberg, P., B. Sundelin, S.-O. Bohman, A. Bobik, H. Nilsson, A. Wickman, H. Gustafsson, J. Petersen, and M. A. Adams. 1994. Renin-angiotensin system in neonatal rats: Induction of a renal abnormality in response to ACE inhibition or angiotensin II antagonism. Kidney Int. 45:485-492.

9. Lewis, E. J., L. G. Hunsicker, R. P. Bain, and R. D. Rohde, for The Collaborative Study Group. 1993. The effect of angiotensin-converting-enzyme inhibition on diabetic nephropathy. N. Engl. J. Med. 329:1456-1462.

10. Cattran, D. C., C. Greenwood, and S. Ritchie. 1994. Long-term benefits of angiotensin-converting enzyme inhibitor therapy in patients with severe immunoglobulin A nephropathy: a comparison to patients receiving treatment with other antihypertensive agents and to patients receiving no therapy. Am. J. Kidney Dis. 23:247-254.

11. Baker, K. M., M. I. Chernin, S. K. Wixson, and J. F. Aceto. 1990. Reninangiotensin system involvement in pressure-overload cardiac hypertrophy in rats. Am. J. Physiol. 259:H324-H332.

12. Clozel, J. P., and F. Hefti. 1988. Cilazapril prevents the development of cardiac hypertrophy and the decrease of coronary vascular reserve in spontaneously hypertensive rats. J. Cardiovasc. Pharmacol. 11:568-572.

13. Anderson, S., H. G. Rennke, and B. M. Brenner. 1986. Therapeutic advantage of converting enzyme inhibitors in arresting progressive renal disease associated with systemic hypertension in the rat. J. Clin. Invest. 77:1993-2000.

14. Kakinuma, Y., T. Kawamura, T. Bills, T. Yoshioka, and I. Ichikawa, and A. Fogo. 1992. Blood pressure-independent effect of angiotensin inhibition on vascular lesions of chronic renal failure. Kidney Int. 42:46-55.

15. Zatz, R., R. Dunn, T. W. Meyer, S. Anderson, H. G. Rennke, and B. M. Brenner. 1986. Prevention of diabetic glomerulonephropathy by pharmacological amelioration of glomerular capillary hypertension. J. Clin. Invest. 77:1925-1930.

16. Anderson, S., T. W. Meyer, H. G. Rennke, and B. M. Brenner. 1985. Control of glomerular hypertension limits glomerular injury in rats with reduced renal mass. J. Clin. Invest. 76:612-619.

17. Lafayette, R. A., G. Mayer, S. K. Park, and T. W. Meyer. 1992. Angiotensin II receptor blockade limits glomerular injury in rats with reduced renal mass. J. Clin. Invest. 90:766-771.

18. Kaneto, H., J. Morrissey, R. McCracken, A. Reyes, and S. Klahr. 1994. Enalapril reduces collagen type IV synthesis and expansion of the interstitium in the obstructed kidney. Kidney Int. 45:1637-1647.

19. Cooper, M. E., J. Rumble, R. Komers, D. He-Cheng, K. Jandeleit, and C. Scheung-To. 1994. Diabetes-associated mesenteric vascular hypertrophy is attenuated by angiotensin-converting enzyme inhibition. Diabetes. 43:1221-1228.

20. Kim, H. S., J. H. Krege, K. D. Kluckman, J. R. Hagaman, J. B. Hodgin, C. F. Best, J. C. Jennette, T. M. Coffman, N. Maeda, and O. Smithies. 1995. Genetic control of blood pressure and the angiotensinogen locus. Proc. Natl. Acad. Sci. USA. 92:2735-2739.

21. Tanimoto, K., F. Sugiyama, Y. Goto, J. Ishida, K. Yagami, A. Fukamizu, and K. Murakami. 1994. Angiotensinogen-deficient mice with hypotension. $J$. Biol. Chem. 269:31334-31337.

22. Hooper, M., K. Hardy, A. Handyside, S. Hunter, and M. Monk. 1987. HPRT-deficient (Lesh-Nyhan) mouse embryos derived from germline colonization by cultured cells. Nature (Lond.). 326:292-295.
23. Remirez-Solis, R., A. C. Davis, and A. Bradley. 1993. Gene targeting in embryonic stem cells. Methods Enzymol. 225:855-878.

24. Hogan, B., R. Beddington, F. Costantini, and E. Lacy. 1994. Manipulating the mouse embryo. 2nd Edition. Cold Spring Harbor Labolatory Press, Cold Spring Harbor, NY 255 pp.

25. Clouston, W. M., B. A. Evans, J. Haralambidis, and R. I. Richards. 1988. Molecular cloning of the mouse angiotensinogen gene. Genomics. 2:240-248.

26. Misono, K. S., L. A. Holladay, K. Murakami, K. Kuromizu, and T. Inagami. 1982. Rapid and large-scale purification and characterization of renin from mouse submaxillary gland. Arch. Biochem. Biophys. 217:574-581.

27. Mercola, M., C. Y. Wang, J. Kelly, C. Brownlee, L. Jackson-Grusby, C. Stiles, and D. Bowen-Pope. 1990. Selective expression of PDGF-A and its receptor during early mouse embryogenesis. Dev. Biol. 138:114-122.

28. Tanaka, R., K. Sugiura, A. Tatematsu, and A. Fogo. 1995. Internephron heterogeneity of growth factors and sclerosis: modulation of platelet-derived growth factor by angiotensin II. Kidney Int. 47:131-139.

29. Pelton, R. W., M. E. Dickinson, H. L. Moses, and B. L. M. Hogan. 1990. In situ hybridization analysis of TGF $\beta 3$ RNA expression during mouse development: comparative studies with TGF $\beta 1$ and $\beta 2$. Development (Camb.). 110:609-620.

30. Kiyama, S., T. Yoshioka, I. M. Burr, V. Kon, A. Fogo, and I. Ichikawa. 1995. Strategic locus for the activation of the superoxide dismutase gene in the nephron. Kidney Int. 47:536-546.

31. Schwartz, S. M., M. K. Majesky, and R. J. Dilley. 1990. Vascular remodeling in hypertension and atherosclerosis. In Hypertension: Pathophysiology, Diagnosis, and Management. G. H. Laragh and B. M. Brenner, editors. Raven Press, Ltd., New York. 521-539.

32. Gomez, R. A., R. L. Chevalier, A. D. Everett, J. P. Elwood, M. J. Peach, and K. R. Lynch. 1990. Recruitment of renin gene-expressing cells in adult rat kidneys. Am. J. Physiol. 259:F660-F665.

33. Johns, D. W., M. J. Peach, R. A. Gomez, T. Inagami, and R. M. Carey 1990. Angiotensin II regulates renin gene expression. Am. J. Physiol. 259:F882F887.

34. Langille, B. L., and F. O'Donnell. 1986. Reductions in arterial diameter produced by chronic decreases in blood flow are endothelium-dependent. Science (Wash. DC). 231:405-407.

35. DiCorleto, P. E., and D. F. Bowen-Pope. 1983. Cultured endothelial cells produce a platelet-derived growth factor-like protein. Proc. Natl. Acad. Sci. USA. 80:1919-1923.

36. Naftilan, A. J., R. E. Pratt, and V. J. Dzau. 1989. Induction of plateletderived growth factor A-chain and c-myc gene expressions by angiotensin II in cultured rat vascular smooth muscle cells. J. Clin. Invest. 83:1419-1424.

37. Gibbons, G. H., R. E. Pratt, and V. J. Dzau. 1992. Vascular smooth muscle cell hypertrophy vs hyperplasia. Autocrine transforming growth factor- $\beta 1$ expression determines growth response to angiotensin II. J. Clin. Invest. 90:456461.

38. Kagami, S., W. A. Border, D. E. Miller, and N. A. Noble. 1994. Angiotensin II stimulates extracellular matrix protein synthesis through induction of transforming growth factor-beta expression in rat glomerular mesangial cells. J. Clin. Invest. 93:2431-2437.

39. Peten, E. P. L. J. Striker, A. Fogo, I. Ichikawa, A. Patel, and G. E. Striker. 1994. The molecular basis of increased glomerulosclerosis after blockade of the renin angiotensin system in growth hormone transgenic mice. Mol. Med. 1:104115 